\title{
Microstructure of Undercooled Pb-Sn Alloys
}

\author{
Walman Benício de Castro ${ }^{a}$, Manuel de Lucena Maia ${ }^{a}$, \\ Claudio Shyinti Kiminami $^{b^{*}}$, Claudemiro Bolfarini $^{b}$ \\ ${ }^{a}$ Departamento de Engenharia Mecânica, UFPB, Campus II \\ ${ }^{\mathrm{b}}$ Departamento de Engenharia de Materiais, UFSCar
}

\begin{abstract}
Melt undercooling opens new solidification pathways for non-equilibrium phases and non-conventional microstructures. Several techniques, including the fluxing technique, have been developed in order to reduce nucleation sites and to produce high undercoolings for metals and alloys. In this work the fluxing technique was applied to $\mathrm{Pb}-25 \mathrm{wt} \% \mathrm{Sn}$ (hypoeutectic), $\mathrm{Pb}-61.9 \mathrm{wt} \% \mathrm{Sn}$ (eutectic) and $\mathrm{Pb}-90 \mathrm{wt} \% \mathrm{Sn}$ (hypereutectic) alloys to investigate the influence of the undercooling on the microstructure of these alloys. For the hypoeutectic alloy, an increasing of the undercooling $\left(\Delta \mathrm{T}_{\mathrm{e}}\right)$ from 7 to $13 \mathrm{~K}$ resulted in interdendritic eutectic refinement. For the hypereutectic alloy, an increasing of undercooling from 8 to $16 \mathrm{~K}$ resulted in a reduction of the $\beta$-Sn primary dendrites arm spacing from $50 \mathrm{~m}$ to $30 \mathrm{~m}$. For the both hypoeutectic and eutectic alloys, an increasing of the undercooling resulted in an interdendritic eutectic with anomalous morphology. The results indicated that the critical eutectic undercooling, $\Delta \mathrm{T}_{\mathrm{e}}{ }^{*}$, that causes a transition from lamellar eutectic to anomalous eutectic in the $\mathrm{Pb}-\mathrm{Sn}$ alloys, is around $6 \mathrm{~K}$.
\end{abstract}

Keywords: undercooling, Pb-Sn alloys, microstructure, fluxing technique

\section{Introduction}

Rapid Solidification Processing (RSP), of metals and alloys, can be established by applying high cooling rates $\left(10^{2}-10^{6} \mathrm{~K} / \mathrm{s}\right)$ or high undercoolings under low cooling rates $(1 \mathrm{~K} / \mathrm{s})$. The later situation occurs when nucleation sites are reduced or even eliminated. Melt undercooling opens new solidification pathways for non-equilibrium phases and non-conventional microstructures ${ }^{1}$. Fluxing technique is one of the techniques that have been developed in order to reduce nucleation and to produce high undercoolings in metals and alloys. In this technique the liquid is immersed in a material that isolates it from contact with the crucible walls and atmosphere, dissolving impurities or changing structures to make them less active. It also doesn't provide heterogeneous nucleation, which can increase the undercooling degree ${ }^{2}$.

The microstructures of important engineering eutectic system, such as $\mathrm{Pb}-\mathrm{Sn}$, are strongly influenced by the undercooling achieved prior to solidification, the nucleation characteristics of the alloy and the cooling rate. Microstructural evolution during solidification of $\mathrm{Pb}-\mathrm{Sn}$ alloys has been examined in few studies ${ }^{3,4}$. Gravity-driven macrosegregation was observed in the studies using meth- ods based on the reduction of catalytic sites ${ }^{4}$. Gravitydriven macrosegregation is typically caused by differences in liquid density due to gradients in composition and/or differences in density between the liquid and solid phases. The density difference between the liquid and solid phases, and the ability of the eutectic to be undercooled, are favorable for the study of macrosegregation and the influence of undercooling on segregation behavior in the $\mathrm{Pb}-\mathrm{Sn}$ system. In the studies involving directional solidification ${ }^{5,6}$ it was observed that the development of controlled eutectic structures is important from the technological viewpoint, since eutectic structures generally give rise to a fine microstructural scale and thus exhibit superior mechanical properties. Besides the nature of the phases formed, the mechanical properties of a given eutectic alloy largely depend upon the eutectic spacing and the volume fraction of the phases. In the studies involving splat-quenched ${ }^{7,8}$ it was observed that the microstructures presented anomalous eutectic morphology because high cooling rate is applied in this process.

In an undercooled melt, the thermal gradient at the solid-liquid interface is negative, and it is directly related to the growth rate ${ }^{9}$. Thus, at a low solidification rate or at a low undercooling, the microstructure is near to equilibrium. However, at a critical growth rate, the diffusion field

*e-mail: kiminami@power.ufscar.br

Trabalho apresentado no $14^{\circ}$ CBECIMAT, Águas de São Pedro, Dezembro 2000. 
becomes shorter in extent than the microstructure scale. The diffusion process becomes localized with respect to the microstructure, and several morphological changes might take place. For example, the regularity of eutectics can be broken, and eutectic anomalous growth can take place or in some cases the primary arm dendrite refinement can occur $^{10}$.

The present paper reports the influence of undercooling on the microstructures of hypoeutectic, eutectic and hypereutectic $\mathrm{Pb}-\mathrm{Sn}$ alloys.

\section{Experimental Procedure}

The Pb-25wt\%Sn (hypoeutectic), Pb-61.9wt\%Sn (eutectic), $\mathrm{Pb}-90 \mathrm{wt} \% \mathrm{Sn}$ (hypereutectic) alloys were prepared, by weighting the appropriate amounts of $99,98 \%$ purity $\mathrm{Pb}$ and Sn. Quartz ampoules containing these metals were purged with argon and sealed under vacuum at $10^{-5}$ Torr. The materials were alloyed in a rocking furnace at $773 \mathrm{~K}$ for $10 \mathrm{~h}$. The ingots were cut into several pieces of approximately $0.4 \mathrm{~cm}^{3}$ in volume $(3 \mathrm{~g})$. The sample and $30 \% \mathrm{P}_{2} \mathrm{O}_{5}$ $20 \% \mathrm{SnO} 50 \% \mathrm{SnF}_{2}(\% \mathrm{~mol})$ flux were loaded in a quartz crucible (10 mm diameter and $60 \mathrm{~mm}$ height) and several cycles of fusion-solidification were applied. The heating rate was about $0.6 \mathrm{~K} / \mathrm{s}$ and cooling rate about $0.5 \mathrm{~K} / \mathrm{s}$. A mineral-insulated $\mathrm{J}$ type thermocouple ( $1.5 \mathrm{~mm}$ diameter) was used for the temperature measurements. The thermocouple was immersed in the melted sample to guarantee accuracy. The nucleation temperature was detected by finding the inflection point in the temperature versus time cooling curve. Cooling curves were recorded by a computerized data acquisition system. Microstructures were characterized by scanning electron microscopy (SEM) and the interlamellar distances of the eutectic microstructure were with resolution of $10^{-7} \mathrm{~m}$. The Fig. 1 shows the experimental apparatus.

\section{Results and Discussion}

Cooling curves for hypoeutectic and hypereutectic alloys showed two nucleation temperatures, one for primary phase dendrites, $\mathrm{T}_{\mathrm{n} 1}$, and one of the eutectic transformation, $\mathrm{T}_{\text {ne. }}$ The eutectic alloy showed just one nucleation temperature. Table 1 shows the undercoolings degree of the primary phase, $\Delta \mathrm{T}_{1}$, and the undercooling of the eutectic, $\Delta \mathrm{T}_{\mathrm{e}}$, obtained for the $\mathrm{Pb}-\mathrm{Sn}$ alloys.

The microstructure of the $\mathrm{Pb}-25 \% \mathrm{Sn}$ (hypoeutectic) alloy (Fig. 2) consisted of primary dendrites of $\mathrm{Pb}$ (light phase in Fig. 1) and interdendritic eutectic. No morphological change in primary $\mathrm{Pb}$ phase dendrites was observed in accordance with the small undercooling reached. However, the interdendritic eutectic presents an anomalous morphology for both the $7 \mathrm{~K}$ and the $13 \mathrm{~K}$ of undercooling samples, and a refinement of the eutectic was observed with the increasing of the undercooling.

The microstructure of the $\mathrm{Pb}-61.9 \% \mathrm{Sn}$ (eutectic) alloy (Fig. 3) presented a coupled growth of the $(\mathrm{Pb}) / \beta \mathrm{Sn}$ eutec-

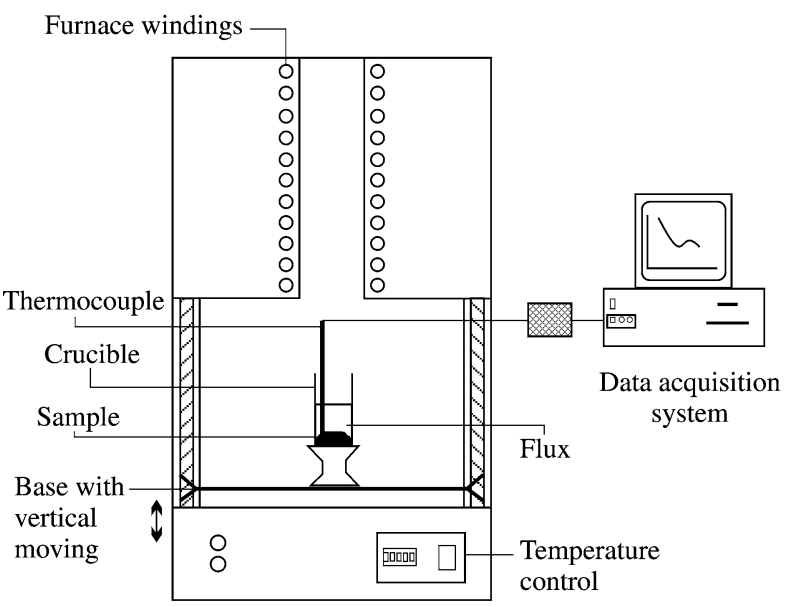

Figure 1. Experimental Apparauts.

Table 1. Undercoolings for Pb-Sn alloys.

\begin{tabular}{lccccc}
\hline $\begin{array}{l}\text { wt\% } \\
\mathrm{S}_{\mathrm{n}}\end{array}$ & sample & $\begin{array}{c}\mathrm{T}_{\mathrm{n} 1} \\
(\mathrm{~K})\end{array}$ & $\begin{array}{c}\mathrm{T}_{\mathrm{ne}} \\
(\mathrm{K})\end{array}$ & $\begin{array}{c}\mathrm{T}_{1}=\mathrm{T}_{\mathrm{L}}-\mathrm{T}_{\mathrm{n} 1} \\
(\mathrm{~K})\end{array}$ & $\begin{array}{c}\mathrm{T}_{\mathrm{e}}=\mathrm{T}_{\mathrm{e}}-\mathrm{T}_{\mathrm{ne}} \\
(\mathrm{K})\end{array}$ \\
\hline \multirow{2}{*}{25} & A & 537 & 449 & 1 & 7 \\
& B & 537 & 443 & 1 & 13 \\
61.9 & A & - & 450 & - & 6 \\
(eutectic) & B & - & 433 & - & 23 \\
& A & 480 & 455 & 8 & 1 \\
90 & B & 472 & 455 & 16 & 1 \\
\hline
\end{tabular}

tic. There is a remarkable change in morphology increasing the degree of undercooling with transition from regular lamellar to anomalous eutectic when the undercooling increases from 6 to $23 \mathrm{~K}$.

The microstructure of the $\mathrm{Pb}-90 \% \mathrm{Sn}$ (hypereutectic) alloy presented primary $\beta S n$ dendrites (dark phase in Fig. 4) and lamellar interdendritic eutectic. Increasing the undercooling from 8 to $16 \mathrm{~K}$ resulted in a reduction of the dendrite arm spacing from $50 \mu \mathrm{m}$ to $30 \mu \mathrm{m}$.

Increasing the undercooling led to a high growth rate in this alloy, hence morphological refinement occurred ${ }^{11}$.

Morphological change and refinement of the eutectic were not observed in hypereutectic alloy in accordance with the small undercooling reached.

The following mechanisms were proposed to explain the dendritic refinement in undercooled samples ${ }^{12}$ : recrystallization due to stresses and/or dislocation; dendrite remelting during recalescence and coarsening; dendrite fragmentation and coarsening. Some works ${ }^{13,14}$ have reported dendritic refinement in undercooled samples, proposing that the most probable mechanism for this phenomenon is dendrite fragmentation. It means that, rapid growing dendrites become morphologically unstable and decay with a reduction of the interface area, as well as the driving force for such a process. This assumption is directly supported by the fact that the dendritic refinement or 

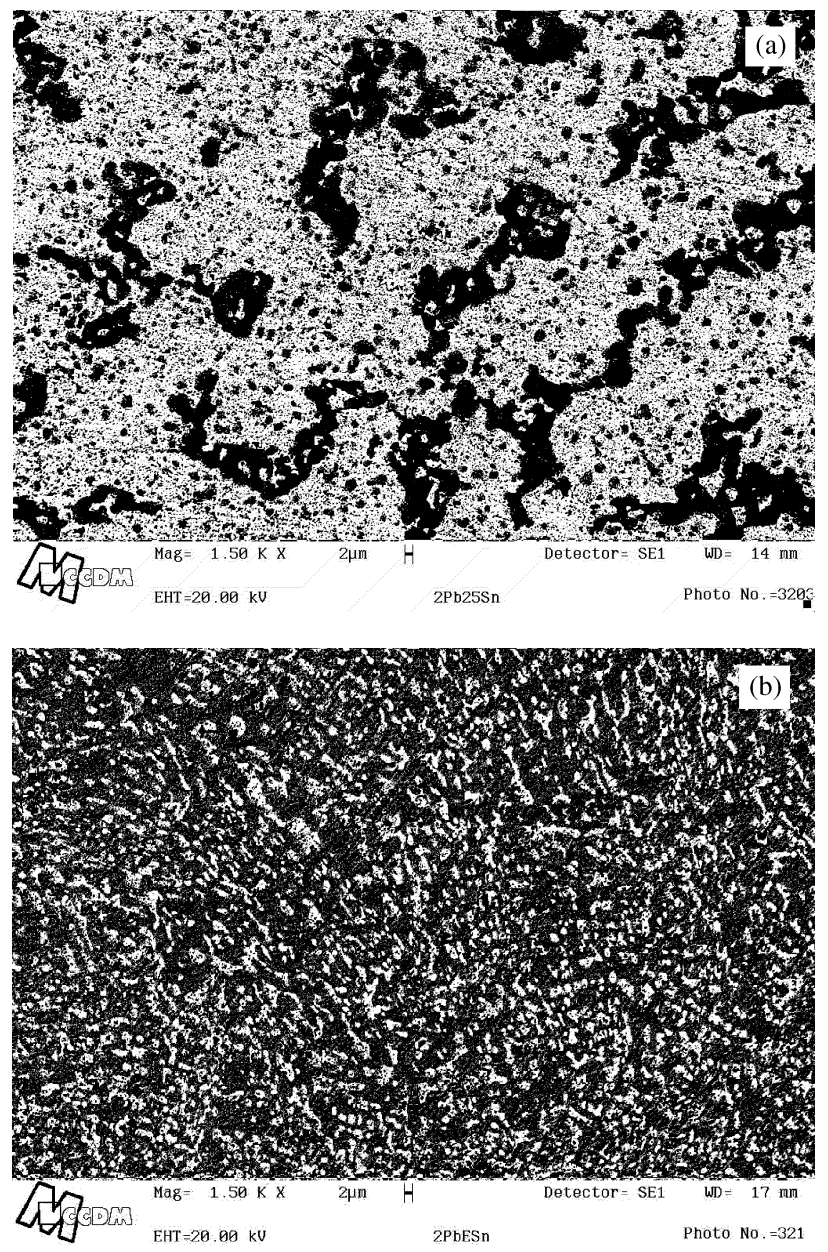

Figure 2. Microstructure of the $\mathrm{Pb}-25 \% \mathrm{Sn}$ alloy. (a) Sample A, $\Delta \mathrm{T}_{\mathrm{e}}=7 \mathrm{~K}$; (b) Sample B, $\Delta \mathrm{T}_{\mathrm{e}}=13 \mathrm{~K}$.

equiaxed grains in highly undercooled samples usually looks like dendrite debris.

It was observed that there is a substantial change in the eutectic morphology with the increasing degree of undercooling. Applying an undercooling of $\Delta \mathrm{T}_{\mathrm{e}}=6 \mathrm{~K}$ to sample A for the eutectic alloy (Fig. 3a) lamellar eutectic is the unique growth morphology, while applying the undercooling of $\Delta \mathrm{T}_{\mathrm{e}}=7 \mathrm{~K}$ to sample $\mathrm{A}$ for the $\mathrm{Sn}-25 \mathrm{wt} \% \mathrm{~Pb}$ (hypoeutectic) alloy (Fig. 2a) anomalous eutectic becomes the unique growth morphology. There is a critical undercooling, $\Delta \mathrm{T}^{*}$ e, for which it occurs a transition from lamellar eutectic to anomalous eutectic in the $\mathrm{Pb}-\mathrm{Sn}$ system. The morphology of the eutectic is lamellar if $\Delta \mathrm{T}_{\mathrm{e}} \mathrm{6 \textrm {K }}$ and anomalous if $\Delta \mathrm{T}^{*} \mathrm{e}$ K. Many studies ${ }^{13,15-17}$ have observed this critical undercooling in other eutectics systems. They have established a variety of propositions to explain the formation mechanisms of anomalous eutectic structures. Thus it is reasonable to conclude that anomalous eutectic is the product of rapid solidification whereas lamellar eutectic forms under slow solidification conditions. The most probable physical mechanism for this phenomenon is that
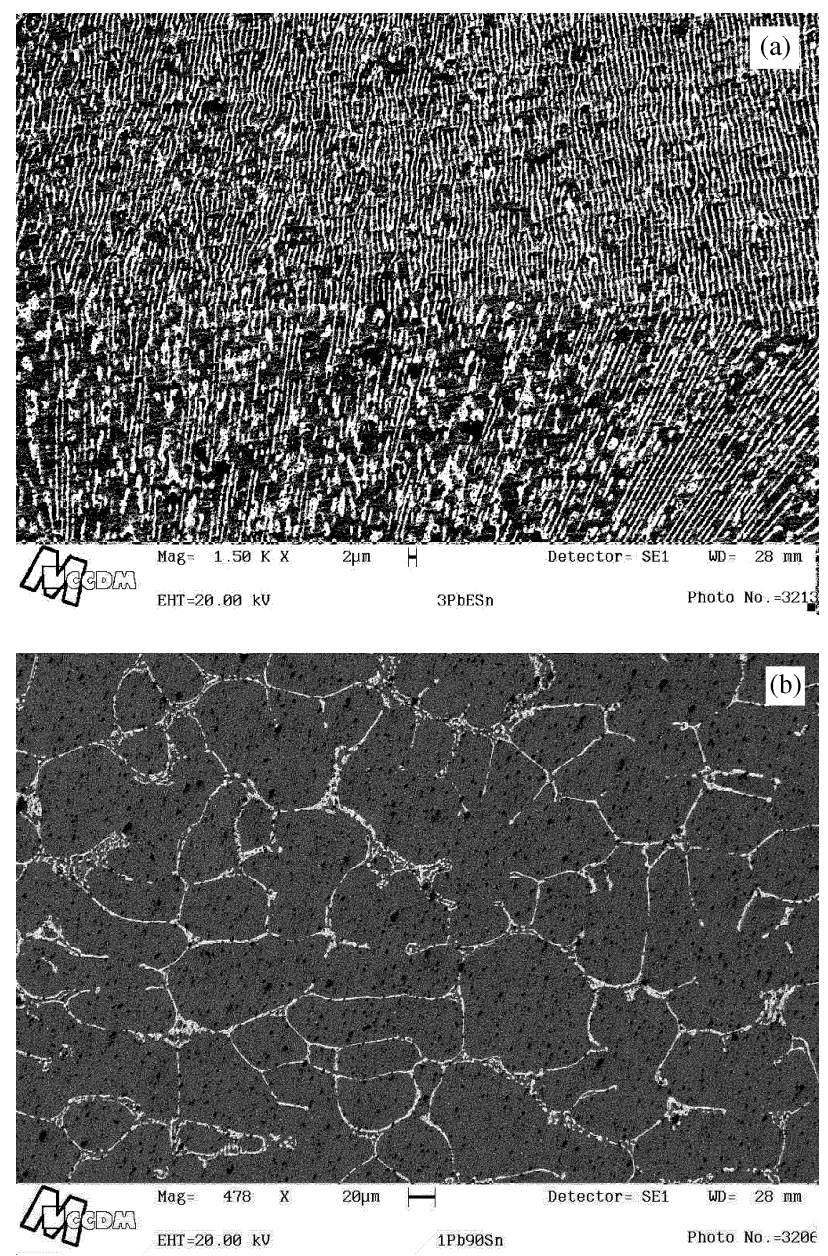

Figure 3. Microstructures of the eutectic alloy. (a) Sample $A, \Delta T_{e}=6 \mathrm{~K}$; (b) Sample B, $\Delta \mathrm{T}_{\mathrm{e}}=23 \mathrm{~K}$.

a considerably high amount of interfacial energy is stored in the fine lamellar eutectic structure in comparison to the gain of volume energy. The reduction of the interfacial energy acts as a driving force for the on going fragmentation mechanism leading to a transformation from the lamellar eutectic microstructure to the equiaxed microstructure of the anomalous eutectic ${ }^{15}$.

Few studies have indicated that $\mathrm{Pb}-\mathrm{Sn}$ system exhibit non-reciprocal nucleating characteristics ${ }^{4,18}$. It means that one primary phase will act as an effective heterogeneous nucleation site for the other phase, but not vice versa. For example, Sundquist and Mondolfo ${ }^{18}$ have found that the primary $\mathrm{Sn}$ phase will readily nucleates $\mathrm{Pb}$ phase at undercoolings between 0 and $0.5 \mathrm{~K}$, while it seems that primary $\mathrm{Pb}$ phase does not nucleates effectively the Sn phase, which produces an undercooling as large as $55 \mathrm{~K}$ for $\mathrm{Sn}$ phase nucleation. The results of the undercooling obtained in this work, shown in Table 1, indicates that it was observed non-reciprocal nucleation. Only one work has applied the fluxing technique to study the $\mathrm{Pb}-\mathrm{Sn}$ system ${ }^{4}$, concluding that non-reciprocal nucleation might be occurred. It is necessary other experiment applying the fluxing technique 

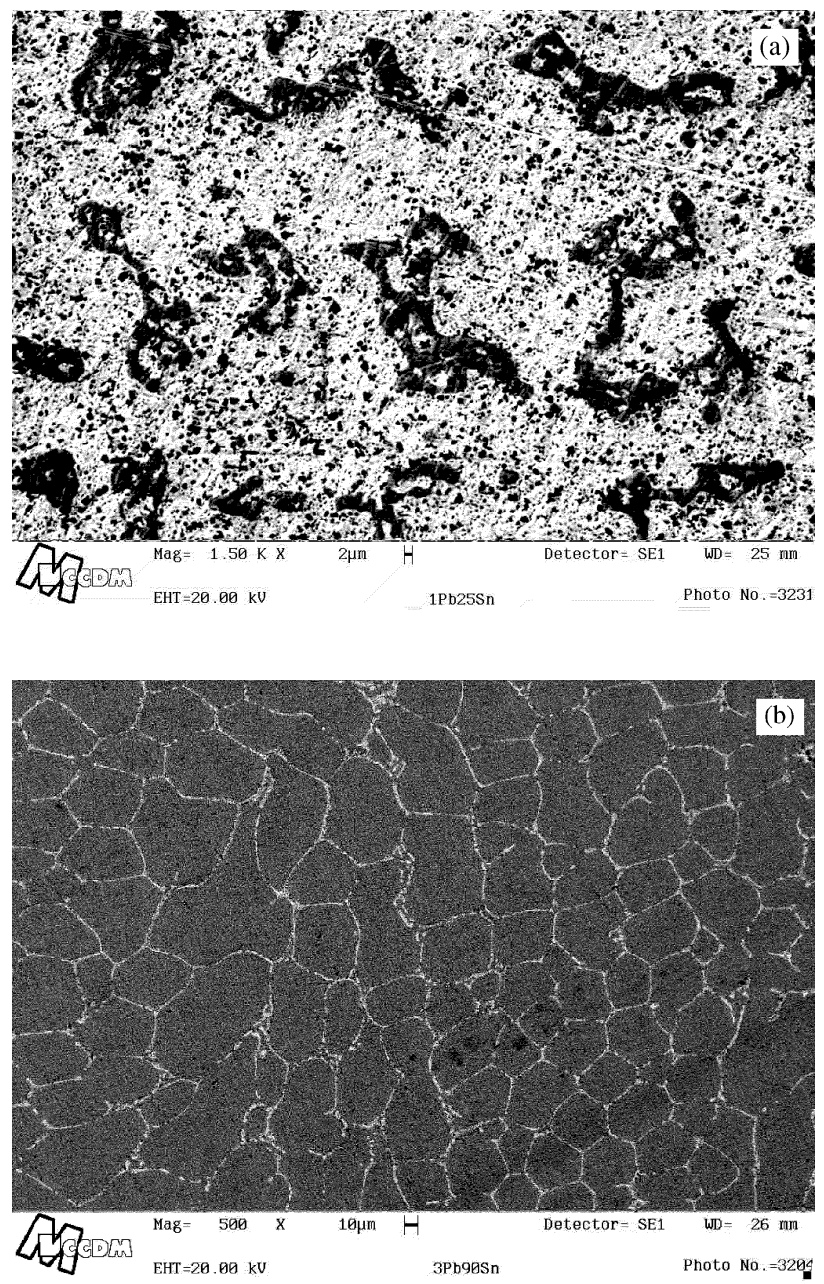

Figure 4. Microstructure of the $\mathrm{Pb}-90 \% \mathrm{Sn}$ alloy. (a) Sample A, $\Delta \mathrm{T}_{1}=8 \mathrm{~K}$; (b) Sample B, $\Delta \mathrm{T}_{1}=16 \mathrm{~K}$.

to confirm if there is or not non-reciprocal nucleation in $\mathrm{Pb}-\mathrm{Sn}$ system.

deGroh and Laxmanan ${ }^{4}$ have also observed macrosegregation in the sample of the eutectic $\mathrm{Pb}$-Sn alloy. They have concluded that in the non-reciprocal nucleation behavior, undercooling and the density differences between the liquid phase $(\mathrm{Sn})$ and the solid phase $(\mathrm{Pb})$ have influenced the macrosegregation. They affirmed that the macrosegregation increases for undercoolings up to $20 \mathrm{~K}$. It was not observed macrosegregation in the eutectic alloy in this work, although the undercooling of the sample B is up to $20 \mathrm{~K}$. It was probably because the small sample volumes used in this work $\left(0.4 \mathrm{~cm}^{3}\right)$, compared with the sample volumes used in the deGroh and Laxmanan work $\left(3 \mathrm{~cm}^{3}\right)$.

\section{Conclusion}

$\mathrm{Pb}-\mathrm{Sn}$ alloys with hypoeutectic, hypereutectic and eutectic compositions have been solidified from the undercooled melt using the fluxing technique. For $\mathrm{Pb}-25 \mathrm{wt} \% \mathrm{Sn}$ (hypoeutectic) alloy, occurred only a refinement of the interdendritic eutectic with increasing undercooling $\left(\Delta \mathrm{T}_{\mathrm{e}}\right)$ from 7 to $13 \mathrm{~K}$. For $\mathrm{Pb}-90 \mathrm{wt} \% \mathrm{Sn}$ (hypereutectic) alloy, only a refinement occurred in the primary $\beta$ Sn dendrites with increasing undercooling. Increasing the undercooling led to a high growth rate in this alloy, hence morphological refinement occurred. The eutectic exhibited anomalous morphology with increasing undercooling $\left(\Delta \mathrm{T}_{\mathrm{e}}\right)$. The results indicated that there is a critical undercooling, $\Delta \mathrm{T}^{*}$, which induces a transition from lamellar eutectic to anomalous eutectic in the $\mathrm{Pb}-\mathrm{Sn}$ system. The morphology of the eutectic is lamellar if $\Delta \mathrm{T}_{\mathrm{e}} \mathrm{6} \mathrm{K}$ and anomalous if $\Delta \mathrm{T} *_{\mathrm{e}} 6$ $\mathrm{K}$. The possible conclusion is that anomalous eutectic is the product of rapid solidification whereas lamellar eutectic forms under slow solidification conditions because a considerably high amount of interfacial energy is stored in the fine lamellar eutectic structure in comparison to the gain of volume energy. The reduction of the interfacial energy acts as a driving force for the on going fragmentation mechanism leading to a transformation from the lamellar eutectic microstructure to the equiaxed microstructure of the anomalous eutectic.

\section{References}

1. Perepezko, J.H.; Uttormark, M.J. ISIJ International, v. 35, p. 580, 1995.

2. Li, M.; Yang, G.; Zhou, Y. Materials Science and Engineering, v. A279, p. 16, 2000.

3. Sem, S.; Dhindaw, B.K.; Curreri, P.A.; Peters, P.; Kaukuler, W.F. Journal of Crystal Growth, v. 193, p. 692, 1998.

4. deGroh III, H.C.; Laxmanan, V. Metall. Trans., v. A19, p. 2651, 1988.

5. Srikanth, S.; Ramachandrarao, P.; Chvoj, Z. Journal of Crystal Growth, n. 208, p. 779, 2000.

6. Tewari, S.N.; Shah, R. Metall. and Materials Trans. A, v. 27A, p. $1353,1996$.

7. Kane, R.H.; Giessen, B.C.; Grant, N.J. Acta Metallurgica, v. 14, p. 605, 1966.

8. Yim, P.; Chun, J-H.; Ando, T.; Sikka, V.K. The International Journal of Powder Metallurgy, v. 32, p. 155, 1996.

9. Kurtz, W.; Trivedi, R. Mat. Sci. Eng., v. A179/A180, p. 46, 1994.

10. Castro, W.B.; Oliveira, M.F.; Kiminami, C.S.; Caram R. Proceedings of the 4th Decennial International Conference on Solidification Processing, Sheffield, v. 1, p. 485, 1997.

11. Kattamis, T.Z. Mat. Sci. Eng., v. A5, p. 531, 1970.

12. Munitiz, A.; Abbaschian, G.J. Proceedings of the International Conference on Solidification, v. 1, p. 23, 1979.

13. Li, J.F.; Zhou, Y.H.; Yang, G.C. Mat. Sci. Eng., v. A277, p. 161, 2000.

14. Wei, B.; Herlach, D.M. Mat. Sci. Eng., v. A226/A228, p. 799, 1997.

15. Goetzinger, R.; Barth, M.; Herlach, D.M. Acta Mater., v. 46, p. 1647,1998

16. Leonhardt, M.; Löser, W.; Lindenkreuz, H.G. Mat. Sci. Eng., v. A271, p. 31, 1999.

17. Abbaschian, R.; Lipschutz, M.D. Mat. Sci. Eng., v. A226/A228, p. 13, 1997.

18. Mondolfo, L.F. The Journal of the Australian Institute of Metals, v. 2 , p. $169,1965$.

FAPESP helped in meeting the publication costs of this article 